\title{
Estilos de Apego como Possíveis Preditores de Estados Motivacionais em Atividades Esportivas de Rendimento: Uma Exploraçáo Teórica
}

Attachment Styles as Predictors of Motivational States in

High-Performance Sport Activities: A Theoretical Exploration

Marcílio Ângelo e Silva

\section{Resumo}

O artigo tem um caráter crítico-teórico exploratório sobre o domínio da psicologia esportiva, no que diz respeito a uma possível nova abordagem de predição de estados emocionais a partir da perspectiva da teoria do apego. Primeiramente, oferece uma revisão sobre a teoria do apego, desde o esboço inicial do precursor da área, o inglês John Bowlby, até as pesquisas mais recentes realizadas em diversos países e sob óticas diferentes. Versa também brevemente sobre aspectos da psicologia, no que concerne à motivaçáo e outros elementos que a influenciam, tais como a emoção e a personalidade. Tece consideraçóes finais apontando um possível caminho promissor para predição de estados motivacionais de atletas de rendimento muito antes da participaçáo dos mesmos em competições, como, por exemplo, a motivação para o êxito ou fracasso. Finalmente apresenta a identificaçáo dos estilos de apego de atletas como forma de predizer as tendências de seus comportamentos nos períodos pré, durante e pós-competição.

Palavras-chave: Estados motivacionais; teoria do apego; psicologia esportiva.

\section{Abstract}

This theoretical article explores the domain of sport psychology domain regarding a possible new approach to the prediction of motivational states from the perspective of the attachment theory. Initially, it reviews such theory from the first contributions of its precursor, John Bowlby, to contemporary scholarship in different countries, as well as their distinct perspectives. It also offers a brief discussion of psychological topics related to motivation and to factors that can influence it, such as emotion and personality. It concludes by suggesting a possible promising way of anticipating motivational states of high performance athletes, such as motivation for failure or success, even before they participate in competitions. Finally, it presents the identification of attachment styles as a promising path for identifying and predicting the behavior of athletes before, during and after a competition.

Keywords: Motivational states; attachment theory; sports psychology.

${ }^{\mathrm{I}}$ Universidade Federal de Pernambuco

A Psicologia Esportiva é um campo de atuação profissional e de investigação científica bastante jovem. Estima-se que em todo mundo haja aproximadamente cinco mil profissionais atuando na área (Samulski, 2009).

Apesar do crescimento incontestável vivido pelaárea [no Brasil] principalmente na última década, muito ainda está para ser feito tanto no que se refere à formaçáo específica do psicólogo do esporte, como em relação ao reconhecimento da importância e necessidade desse profissional nas diversas frentes em que ele pode atuar (Rubio, 2007, p. 10).

É comum encontrar na literatura livros com capítulos específicos dedicados à apresentação de teorias da motivação, assim como artigos que versam sobre o tema. Apenas a partir da década de 1980 pôde-se verificar um crescimento maior de iniciativas de pesquisa no Brasil e uma menor dependência da produção acadêmica vinda de países da Europa e dos Estados Unidos (Rubio, 2007).

Numa breve revisão sobre os aspectos mais pesquisados na Psicologia Esportiva no Brasil é possível identificar estudos sobre: níveis de ansiedade em jogadores de futebol (Román \& Savoia, 2003); análises do comportamento aplicadas ao esporte e à atividade física (Cilo, 2002): Psicologia do Esporte como campo de trabalho para os psicólogos (Epiphanio, 1999); histórico e áreas de atuação da pesquisa da Psicologia do Esporte (Rubio, 1999); treinamento desportivo e Psicologia do Esporte (2000); aspectos atuais e futuros da Psicologia do Esporte (Rubio, 2007); o que é a Psicologia do Esporte (Sousa Filho, 2000); a influência dos pais na carreira esportiva de crianças e adolescentes (Vilani \& Samulski, 2002); espírito esportivo entre universitários de Educação Física e Psicologia 
(Santos, 2001); espírito esportivo, fair play e a prática de esportes (Santos, 2005); motivação para a prática esportiva (Samulski \& Noci, 2002); teorias da motivação aplicada ao esporte (Samulski, 2009); e a prática esportiva como promotora de resiliência psicológica (Sanches, 2007).

Diante de tal panorama, é plausível afirmar que são raríssimas as iniciativas de pesquisa que tenham abordado de alguma forma a teoria do apego na área esportiva. Da produção científica anteriormente citada, nenhuma faz uso desta teoria como possível caminho para compreender o comportamento de atletas, seus estados motivacionais ou qualquer outro aspecto psicológico de desportistas. Apenas o trabalho de Sanches (2007) faz uma breve menção à teoria do apego em sua fundamentação teórica. No campo internacional, a dificuldade de encontrar estudos que englobem os aspectos do apego e da prática esportiva tende a reproduzir a realidade brasileira, com exceçáo de estudos como o de Carr (2009), sobre as implicaçóes da teoria do apego para o esporte e a prática esportiva.

Destarte, a presente iniciativa vem ao encontro de uma demanda decorrente de um gap teórico existente na Psicologia do Esporte, e visa a contribuir para o robustecimento dessa área. Baseia-se na premissa de que a teoria do apego pode oferecer insights valiosos para a compreensão do comportamento de atletas e de aspectos referentes a seus estados ou atitudes motivacionais diante de situaçôes estressantes, tais como as competiçóes esportivas, como também abrir espaço para novos caminhos de intervenção.

\section{Principais Aspectos da Teoria do Apego e sua Evoluçáo}

A teoria do apego começou a ser formulada e divulgada na segunda metade do século passado, pelo psicanalista e psiquiatra inglês John Bowlby. Em 1969, quando Bowlby publicou seu primeiro livro, Attachment and Loss, iniciou-se aquilo que viria a ser conhecido no mundo todo como uma maneira diferente e abrangente de explicar o desenvolvimento sócio-afetivo-emocional do ser humano. Posteriormente, Bowlby publicou outros dois livros, em 1973 e 1980, completando a trilogia Attachment and Loss, a qual continha todo o arcabouço necessário para o desenvolvimento de sua teoria.
A partir de várias perspectivas teóricas, especialmente da Biologia Evolucionária, da Etologia e da Psicanálise, e de observaçôes sistemáticas das relaçóes primárias da díade mãe-filho(a), Bowlby começou a elaborar certos postulados, os quais se propunham a explicar como se dava o desenvolvimento humano no campo sócio-afetivoemocional. Para Bowlby, o ser humano nasce com um sistema comportamental filogeneticamente herdado que serve de estratégia de preservação de sua raça. Enquanto outros animais desde que nascem conseguem de imediato efetuar certas açóes, como caminhar e pressentir o perigo buscando abrigo para se proteger, o ser humano dispóe apenas de elementos comportamentais que se apresentam mais como sinais ou alertas de uma necessidade eminente do que como uma ação independente na busca da solução de um problema. Em outras palavras, o ser humano depende da açáo concreta de outros seres humanos para que possa sobreviver. Este sistema de sinais ou alertas Bowlby denominou de comportamento de apego. Este comportamento é, portanto, um mecanismo inato que tem como objetivo aproximar o bebê, apenas nascido, de sua mãe, a qual servirá inicialmente como agente protetor, no sentido mais amplo da palavra. Com o passar do tempo, a relação mãe-bebê se torna um vínculo afetivo, e a mãe passa a representar a figura de apego inicial do infante. Deste vínculo afetivo, ou seja, desta relação inicial mãe-bebê, emergirá no indivíduo um modelo representacional de si mesmo, dos outros e do mundo que o cerca, modelo este denominado Internal Working Model (IWM), ou Modelo Interno de Funcionamento. Tal modelo se delineará de várias maneiras, dependendo da qualidade dos primeiros contatos e das relaçóes de cuidado do bebê com sua mãe ou cuidador (Bradford \& Lyddon, 1994). Assim como o sistema de comportamento de apego permanecerá ativo durante toda a vida do indivíduo, o IWM permanecerá bastante estável, embora não imutável (Bowlby, 1969, 1973, 1980).

Depois de estabelecidos os pressupostos iniciais de sua teoria, muitas pesquisas foram se desenvolvendo no mundo, mas foi a de Mary Ainsworth e colaboradores que trouxe uma contribuição significativa para o robustecimento da teoria do apego. Ao investigar na Uganda relaçóes primárias de muitas mães e filhos(as), Ainsworth et al., utilizando-se de um método experimental novo criado por eles e conhecido mundialmente como 
"strange situation", identificaram estratégias diferentes de comportamento de apego das crianças em relação às suas figuras de apego. Tais estratégias de apego foram classificadas segundo ainsworth et al. como sendo: estilo de apego "seguro" e "inseguro"; este tendo ainda uma subdivisão, "ansioso" e "evitante". Main \& Hesse (1990) apontam ainda um quarto estilo de apego, o qual foi chamado de "desorganizado".

$\mathrm{O}$ apego seguro se desenvolve quando a mãe ou cuidador(a) se torna uma base segura a partir da qual a criança pode explorar o ambiente que a rodeia, sem temer a ausência de um apoio ou proteção por parte de quem cuida da mesma, caso algo venha a ameaçar a integridade da criança. $\mathrm{O}$ apego inseguro do tipo ansioso se desenvolve quando a relaçáo mãe-criança ou cuidador(a)-criança ora corresponde às demandas da criança de forma consistente, ora náo, isto, por sua vez, gera um nível de ansiedade na criança, já que esta passa a náo ter certeza de que quando precisar de apoio seguro, a máe ou cuidador(a) estará presente para protegê-la ou ajudá-la. $\mathrm{O}$ apego inseguro do tipo evitante se desenvolve quando a relação mãe-criança ou cuidador(a)-criança se dá de forma distanciada, ou seja, a mãe raramente ou nunca se mostra presente diante das necessidades de proteção da criança. O estilo de apego desorganizado se desenvolve quando aquele(a) que deveria servir como base segura para a criança se torna uma fonte de ameaça à integridade física e emocional da mesma; geralmente isso ocorre em ambientes onde a criança sofre abusos por parte dos próprios pais ou cuidadores. De maneira geral, pessoas com estilo de apego inseguro do tipo ansioso hiperativam o mecanismo de estratégias de regulaçáo do afeto, enquanto as que desenvolvem o do tipo evitante desativam tal mecanismo (Ein-Dor, Mikulincer, Doron \& Shaver, 2010). Segundo Ainsworth (1989), é o padrão de aproximação mãe-filho(a), e não a frequência, que vai predizer que tipo de vínculo afetivo ou apego se estabelecerá com o tempo. Portanto, o fator principal no estabelecimento de um ou de outro estilo de apego é a qualidade da relação mãe-filho(a) ou cuidador(a)-filho(a). De fato, Shomaker e Furman (2009) apontam que a segurança nas primeiras relações de apego entre filhos e pais está associada a uma maior competência social, amizades qualitativamente positivas e popularidade na infância e na adolescência.

Atilli, Vermigli e Roazzi (2011) desenvolveram um estudo na Itália no qual analisaram a influência dos estilos de apego de genitores no status social e comportamento de crianças de sete a nove anos. Ele aponta para o fato de que crianças com pais que apresentavam comportamento positivo, como o de encorajar e ajudar seus filhos(as), apresentaram maior habilidade para começar e manter bons relacionamentos com seus pares.

Uma das explicaçóes para a transferência das relaçóes positivas ou negativas entre pais e filhos(as) para outros relacionamentos está no argumento de que crianças e adolescentes criam modelos representacionais de como devem ser as relaçóes com seus pares a partir de suas vivências com os próprios pais e dos exemplos dos relacionamentos entre os pais $(\mathrm{Ng}$ \& Smith, 2006; Shomaker \& Furman, 2009). Obegi, Morrison e Shaver (2004) afirmam que o mecanismo responsável pela transmissão intergeneracional de estilos de apego de pais para filhos(as) é, ao menos em parte, a qualidade dos cuidados dados pelos genitores, os quais são moldados pelos próprios estilos de apego destes. Ein-Dor et al. (2010) (citado por Main, Kaplan \& Cassidy, 1985) apontam que a qualidade das interaçóes entre pais e filhos medeia a transmissão intergeneracional do apego.

Apesar de existirem controvérsias sobre o aspecto da generalização dos padrôes de interação primários para relaçóes futuras, durante o ciclo vital, estudos longitudinais diversos (Fonagy, 1999) têm demonstrado a estabilidade do apego, tanto na adolescência como na vida adulta. (Dalbem \& Dell'Aglio, 2006, p. 8).

Dalbem e Dell'Aglio (2008) oferecem uma descrição dos padróes de estilos de apego que se apresentam na adolescência. No padrão seguro/ autônomo, adolescentes apresentam facilidade de comunicação, de exprimir seus sentimentos com clareza, baixos sinais de ansiedade e depressáo, autoconfiança, facilidade de interagir socialmente, percepçáo positiva dos outros e do mundo. No padrão evitativo/desapegado, adolescentes tendem a idealizar suas experiências de infância ao mesmo tempo em que têm dificuldades de se lembrar de certas experiências daquele período. Apresentam severidade na autocrítica, distanciamento emocional, hostilidade nos relacionamentos, desconfiança dos outros, percepção negativa das pessoas e positiva de si mesmos, entre outros. No padrão preocupado/ ansioso, os adolescentes apresentam relatos vagos 
e inconsistentes de experiências da infância, baixa autoestima, percepção positiva dos outros, sinais de depressão, relacionamentos afetivos conflituosos, tendência à introversão, entre outros. No padrão desorganizado/desorientado, os adolescentes apresentam sinais de desorganizaçáo, relatos de vivências negativas em predominância, apontam seus cuidadores como fonte de ameaça e/ou medo, incongruência afetiva, entre outros.

Num estudo realizado por Davis, Shaver e Vernon (2003) sobre reaçôes físicas, emocionais e comportamentais diante do evento de término/ perda de relacionamento romântico entre adultos, os autores enfatizam que existem três estratégias básicas de enfrentamento. Os de padrão seguro tendem a expressar seus sentimentos abertamente para seu (sua) companheiro(a), a procurar amigos ou familiares para buscar conforto emocional, além de demonstrarem mais capacidade de entendimento sobre a decisão de quem termina o relacionamento, respondendo de forma não agressiva ao evento. Os de padrão evitante tendem a não expressar qualquer tipo de emoção, como a raiva, além de não procurar apoio por parte de outras pessoas e não insistir para manter o relacionamento; tendem a se livrar de coisas e lugares que venham a lembrar o(a) outro(a), a se culpar pelo término do relacionamento e a fazer uso de estratégias antissociais para lidar com o problema, como se embriagar e fazer uso de drogas. Os de padrão ansioso tendem a apresentar comportamento agressivo ou sedutor para reatar o relacionamento, a chorar demasiadamente e até mesmo a gritar, como também a fazer cara de inocente e indefeso para comover o outro.

Tais estratégias estão estreitamente relacionadas aos estilos de apego de cada participante da relação romântica. Esses estilos de apego adultos, por sua vez, seriam uma consequência da estabilidade dos IWM surgidos na infância, e que passam a guiar, na fase adulta e em relacionamentos românticos, diversas maneiras de "negociar" as interaçóes nos tipos de relacionamento que estabelecemos durante a vida (Obegi, Morrison \& Shaver, 2004). No mesmo sentido, Ng e Smith (2006) citado por Cohn et al. (1992) ressaltam que casais com estilos de apego inseguro se encontram mais frequentemente em relacionamentos conflituosos e em relacionamentos pais-filhos(as) menos efetivos.

Um estudo recente sobre a confiança de crianças nas explicaçóes de suas mães referentes a aspectos diversos em comparação com aquelas dadas por uma pessoa estranha constatou que a confiança das crianças nas orientaçóes de suas mães é influenciada pelos estilos de apego. Corriveau et al. (2009) afirmam que crianças com estilos de apego seguro, de forma geral, tendem a confiar mais nas suas mães dos que em estranhos quando elas apresentam dicas e explicaçôes com pistas coerentes, mas também acreditam em estranhos quando seus argumentos são mais convincentes; crianças com estilos de apego ansioso-evitante tendem a não confiar em suas mães independentemente do fato de as respostas dadas por elas serem mais coerentes do que as dos estranhos; e crianças com estilos de apego ansiosoambivalente tendem a confiar mais nas suas mães, independentemente de as respostas dadas por elas serem mais coerentes do que as dos estranhos.

Tais evidências se mostram de acordo com as premissas da teoria do apego, pois se os estilos de apego se desenvolvem a partir das relações de correspondência em apoio e afeto dos pais quando seus filhos apresentam necessidades físico-afetivoemocionais, é de se esperar que naqueles casos em que a criança não pode confiar na estabilidade e frequência de responsividade de seus pais, as mesmas desenvolvam desconfiança nos seus genitores e transfiram esse sentimento para outras situaçóes do cotidiano.

De forma geral na literatura, o estilo de apego seguro está associado a uma maior probabilidade de ajustamento sócio-afetivo-emocional, enquanto o estilo de apego inseguro com suas variaçôes, assim como o desorganizado, está associado a uma série de psicopatologias e a comportamentos instáveis e antissociais, como também à instabilidade emocional. Éthier, Lacharité e Couture (1994) afirmam, por exemplo, que crianças que passam por experiências estressantes durante a infância, as quais envolvam abusos físicos, crueldade emocional, disciplina rígida e desamorosa, abuso sexual, negligência e apoio emocional limitado e inconstante, geralmente possuem pais que passaram por experiências negativas na sua própria infância. Os mesmos autores ainda ressaltam que náo é a quantidade de eventos negativos na infância que predirá o nível de incapacidade dos pais em dar afeto necessário e educaçáo equilibrada para seus filhos, mas sim a intensidade emocional dessas experiências e suas consequências para o desenvolvimento da pessoa. Aqui, o que decorre à luz da teoria do apego é que tais experiências negativas podem gerar um nível de ansiedade e de estresse 
extremamente alto nas crianças. Isto, por sua vez, facilita a emergência de estilos de apego inseguros ou desorganizados. Ademais, a prerrogativa de que seja possível uma transferência intergeneracional de estilos de apego corrobora o argumento anterior.

No entanto, num estudo inovador a respeito dos aspectos positivos e benefícios provenientes de todos os estilos de apego, Ein-Dor et al. (2010) propóem uma nova teoria chamada Social Defense Theory (SDT), ou Teoria da Defesa Social. Esses pesquisadores afirmam que várias pesquisas no campo da teoria do apego têm apontado para o fato de que $33 \%$ da população mundial (ou 2 bilhóes de pessoas) possuem estilos de apego inseguro, e que, tomando como referencial tal indicativo seria uma contradição associar os estilos de apego inseguros apenas com aspectos negativos, pelo menos do ponto de vista evolutivo. $\mathrm{O}$ raciocínio empregado por aqueles autores é que, durante a evolução humana, pessoas que possuíam estilos de apego inseguros, ou seja, o ansioso e o evitante, como também o estilo de apego seguro, teriam cada qual um papel importante na preservaçáo de seus pares. Ao mesmo tempo, aqueles com estilo de apego seguro serviriam para manter a coesão e o equilíbrio emocional do grupo.

Os que possuíam estilo de apego inseguro ansioso, por exemplo, por apresentarem alto nível de ansiedade diante de ameaças e perigos, desencadeariam reaçóes ou scripts de sentinelas, alertando os outros em relação ao perigo emergente. Já os que possuíam estilo de apego inseguro evitante, por apresentarem um distanciamento emocional dos outros e uma atitude bastante individualista, desencadeariam reaçóes ou scripts do tipo fight-flight (lutar ou correr), o que, por consequência, facilitaria a busca de alternativas de fuga, mesmo que a intenção inicial tenha sido apenas de se salvar primeiro. Todas essas atitudes e reaçóes aumentariam, portanto, as chances de sobrevivência em um tempo em que as ameaças à integridade física do ser humano eram mais severas.

$\mathrm{Se}$ as evidências científicas sobre a plausibilidade da SDT aumentarem, a mesma poderá servir como um passo a frente no entendimento sobre a verdadeira funçáo do ponto de vista social de cada estilo de apego. Certamente, novos questionamentos e respostas virão à tona. Porém, já considerando a pertinência dos argumentos da SDT, sua lógica poderá ser utilizada nas mais diversas áreas e funçôes sociais, como na seleção de pessoal para determinadas funções e cargos profissionais.
Outro aspecto que vem sendo abordado mais recentemente é a importância da figura do pai nas relaçôes de apego. Punyanunt-Carter (2006) enfatiza de modo especial o fato de que poucas pesquisas nesta área direcionam o olhar para a relação pai-filha, e que a maior parte das pesquisas que envolveram o estudo da manutençáo de relacionamentos está voltada a casais ou a relacionamentos românticos. Num estudo compreendendo 250 mulheres com idades entre 18 e 35 anos, com pais vivos, PunyanuntCarter não encontrou evidências de que os estilos de apego de pais e filhas influenciam o comportamento de manutenção de relacionamento entre eles. Tacón e Caldera (2001) e Mallinckrodt e Wang (2004) afirmam que existem variaçóes cross-culturais na distribuição e no comportamento de apego, o que póe em questão a universalidade dos princípios da teoria do apego, e que pouco se investigou sobre as populaçóes hispânicas. Num estudo envolvendo 155 estudantes universitárias americanas de descendência mexicana e de etnia branca não-mexicana, com o intuito de investigar aspectos dos relacionamentos entre pais e filhas, Tacón e Caldera (2001) descobriram que as mães inicialmente obtiveram escores maiores em relação ao histórico de cuidados afetuosos para os dois grupos de universitárias. No entanto, os escores se invertiam em termos de relevância da figura de apego quando se tratava das universitárias (de descendência mexicana e não-mexicana) que se encontravam no período final da adolescência, ou seja, os pais passavam a ter um papel mais importante na relação de apego com as filhas. Tais achados levaram aqueles autores a propor que as relaçóes de apego entre genitores e filhos(as) seriam do tipo holotropic (se comportando como um holograma), com a participação dessas figuras de apego se alternando em importância durante o ciclo de vida de seus filhos(as).

Os achados sobre o histórico diferente de cuidados paternais e maternais mostram essa singular combinação holotrópica, que se funde para influenciar mais tarde o desenvolvimento do apego; náo é apenas uma figura de apego no status hierárquico, mas é o resultado totalizante do caleidoscópio organizacional do apego que gera a força do desenvolvimento (Tacón \& Caldera, 2001, p. 83).

Recentemente, Atilli, Vermigli e Roazzi (2011) analisaram associaçóes entre os IWM de pais e mães, 
a qualidade das relaçóes destes com seus filhos e a aceitação social dos filhos no que diz respeito à aceitação ou à rejeição dos mesmos por parte de seus pares. O estudo dos pesquisadores envolveu 44 casais italianos e seus filhos, com idades compreendidas entre sete e nove anos, e foi realizado a partir de observaçóes diretas no ambiente intrafamiliar dos participantes. Os achados da pesquisa segundo os autores indicam que casais nos quais ambos os pais possuem estilos de apego seguros apresentam comportamentos positivos com menos críticas e interferências, e tendem a oferecer um ambiente familiar de segurança, com mais encorajamento, ajudando os seus filhos, proporcionando conforto físico e mental e proteção de forma geral. Como consequência, filhos de genitores com modelos mentais seguros são bem aceitos entre seus pares.

Naqueles casais cujos pais apresentam um modelo mental seguro e as mães um modelo inseguro, a tendência é que o modelo mental seguro do pai, além de promover a competência global dos dois genitores, sirva também como proteção aos filhos, pois a influência do mesmo ajuda a mãe com estilo de apego inseguro a se comportar de forma mais afetuosa e participante. Desta forma, os filhos de casais que apresentam estilos de apego seguro e inseguro náo se diferenciam de maneira significativa daqueles cujos ambos os pais possuem estilos de apego seguros; ou seja, os filhos também são bem aceitos entre seus pares. A pior situação, de acordo com os resultados da pesquisa de Atilli, Vermigli e Roazzi (2011), são aqueles casais em que ambos possuem estilos de apego inseguro, pois tendem a apresentar comportamentos negativos e a oferecer um ambiente familiar instável para seus filhos, o que acarreta a instabilidade emocional destes. Como consequência, seus filhos tendem a ser mais rejeitados entre seus pares. Os resultados da pesquisa são importantes, pois apontam indícios claros de que os modelos mentais de genitores constituem e moldam a natureza da relação parental, como também a relação genitores-filhos(as). E a partir da evidência de maior ou menor competência social dos filhos como influência dos estilos de apego de seus pais em sua totalidade, ratifica-se assim a ideia da transferência intergeneracional dos IWM dos pais para seus filhos.

Muitos dos aspectos abordados anteriormente têm implicaçôes diretas para o domínio da motivação, como é o caso do estudo de Dalbem e Dell'Aglio (2008), o qual aponta os estilos de apego como elementos influenciadores de vários aspectos psicológicos, como a autoconfiança, a autoestima, níveis de ansiedade, entre outros. Estas, por sua vez, são variáveis que têm impacto direto em aspectos comportamentais, como a motivação. No entanto, antes de tecer qualquer argumento de ligação entre a teoria do apego e a motivação, faz-se necessário abordar alguns conceitos pertinentes à mesma.

\section{Motivaçáo e Algumas de suas Nuances}

\begin{abstract}
Não é difícil ver porque motivação se tornou uma das áreas centrais de investigação dos psicólogos. A ciência da Psicologia não é por acaso definida como o estudo do comportamento humano (Evans, 1975, p. 9).
\end{abstract}

De um modo geral, elementos como impulsos e instintos, assim como propósitos e intençôes, são agentes influenciadores do comportamento humano (Evan, 1975; Vernon, 1969). Os impulsos e instintos estão mais associados ao comportamento não intencional. Já os propósitos e intençôes estão mais associados ao comportamento intencional. Estes últimos são, por sua vez, fortemente relacionados e influenciados por incentivos, metas e recompensas; em outras palavras, estímulos (Evans, 1975). Destarte, estímulos podem ser considerados como elementos motivadores do comportamento humano, como motivos. No entanto, existem outros elementos, tais como as vontades e as necessidades de uma pessoa, as quais também influenciam o comportamento. Portanto, considerando o que foi descrito até agora, é plausível afirmar que a motivação pode tomar duas formas distintas: a intrínseca (vontades e necessidades) e a extrínseca (incentivos e recompensas) (Reeve, 2005; Parkinson \& Colman, 1995; Deci, 1976). No caso de atletas de rendimento, as duas formas de motivaçáo podem estar presentes. Por exemplo, um atleta pode estar motivado a dar seu máximo por uma recompensa externa (uma medalha de ouro nas olimpíadas), assim como por uma recompensa interna (autorrealização por meio da autossuperação).

Segundo Samulski (1995), “a motivação é caracterizada como um processo ativo, intencional e dirigido a uma meta, o qual depende da interação de fatores pessoais (intrínsecos) e ambientais (extrínsecos)". Segundo esse modelo, a motivação apresenta uma determinante energética (nível 
de ativação) e uma determinante de direção do comportamento (intençôes, interesses, motivos e metas) (Samulski, 2009, p. 168).

Outro aspecto que pode influenciar a motivação é a emoção. Vernon (1969) sugere que alguns tipos de emoção podem direcionar o comportamento, e outros não.

Solidarizar pode ser um pouco mais do que um registro passivo das emoçóes de outras pessoas, acompanhado de emoçóes correspondentes; por outro lado, compaixão nos estimula a fazer algo para aliviar a infelicidade de alguém. No entanto, todas as emoçóes nos permitem avaliar objetos e eventos, e julgar os significados dos mesmos para nós. Elas podem até nos permitir entender mais compreensivamente do que a razão por si só, especialmente em situaçóes envolvendo desejos e açóes de outras pessoas. Ademais, as emoçóes tornam possível a avaliação de nossas próprias açôes, nos estimulando assim a persistir em determinados cursos de ação que possam nos parecer valiosos, enquanto desistir de outros que possam nos ser sem valor ou ameaçadores (Vernon, 1969, p. 72).

O argumento acima tem importância considerável para o entendimento sobre a relação entre as emoçóes e o comportamento humano. Aparentemente, as emoçóes podem ser influenciadas e até mesmo condicionadas por estímulos externos, como o ambiente social e a cultura (Pickton \& Broderick, 2005; Belch \& Belch, 2004; Steenkamp, 2001). Em consonância, Parrott (2001) afirma que nossas emoções têm um efeito sobre outras pessoas; elas são reguladas por regras e papéis sociais e modificadas pela cultura. Assim, é plausível afirmar que o comportamento que apresentamos nas diversas situaçôes do dia a dia é resultado de fatores socioculturais, os quais inclusive direcionam o modo como nossas emoçóes se expressam. Considerando que o primeiro contato com aspectos socioculturais se dá no núcleo familiar, então é a partir das primeiras interaçôes nesse ambiente que nossas emoçôes e comportamentos são moldados. Tal argumento encontra-se em estreita consonância com o que foi explanado anteriormente na revisão de literatura sobre a teoria do apego, principalmente no que se refere ao IWM (Modelo Interno de Funcionamento), que é determinante para a formação da personalidade humana.

Assim como pesquisadores da área da teoria do apego apontam para o fato de que os estilos de apego se tornam relativamente estáveis durante a vida do indivíduo, Mowen e Minor (1998) afirmam que, para se definir personalidade, quatro aspectos essenciais precisam ser considerados: o comportamento apresenta consistência através do tempo; o comportamento é contextual; um simples aspecto da personalidade não autoriza a predição de um comportamento; estes fatores fazem com que as pessoas sejam distintas entre si. Blythe (1997, p. 39) enfatiza que a personalidade "é o conjunto de características individuais que fazem a pessoa ser única e que controlam as respostas da mesma no ambiente ao seu redor". Ora, se a personalidade controla nossas respostas ao ambiente, ela, por sua vez, tem uma ligação com aquilo que nós filtramos como sendo estímulos importantes ou não. Por consequência, aquilo que nos motiva a fazer algo ou não.

Considerando o que foi dito até o presente, se aspectos motivacionais são influenciados pelas emoçóes, as quais influenciam nosso comportamento, e se nosso comportamento é influenciado pela nossa personalidade, a qual se constitui através de interaçôes sociais num determinado ambiente cultural, podemos argumentar também que nossos estilos de apego, os quais moldam nossa personalidade, determinam a maneira como nossas emoçóes se expressam e, por consequência, nossos estados motivacionais. Portanto, é plausível afirmar que a motivação de cada pessoa é diretamente influenciada pelos seus estilos de apego. No entanto, no que concerne às investigaçôes no campo da motivação na área desportiva, pode-se afirmar que nenhuma iniciativa foi feita até o momento para explorar a influência dos estilos de apego na motivaçáo de atletas de alto rendimento. A teoria da necessidade para o rendimento (need achievement theory), de Atkinson (1974) e McClelland (1961), citada por Samulski (2009), explica a motivação como o resultado da interação entre fatores pessoais e situacionais, o que se aproxima muito do conceito de motivação intrínseca e extrínseca. A teoria da 
atribuição (attribution theory) foca na interpretação de atletas sobre as causas para seu fracasso ou sucesso. A teoria das metas para o rendimento (achievement theory) aponta a interação de três fatores como sendo determinantes para o nível de motivação dos atletas: as metas para o rendimento, a percepção subjetiva das próprias capacidades e o comportamento do rendimento. A teoria da motivação para a competência (competence motivational theory) explica o processo de interação entre a percepção de competência, o controle pessoal e o estado de motivação de um indivíduo. A teoria de Heckhausen de motivação para o rendimento aponta duas tendências motivacionais em atletas de alto rendimento: procurar o êxito e evitar o fracasso (Samulski, 2009).

De modo geral, as teorias motivacionais mais conhecidas no campo do desporto estão umas mais e outras menos focadas em aspectos comportamentais resultantes de fatores internos ao indivíduo, como a maneira pela qual se interpreta um resultado, a percepçáo subjetiva das próprias capacidades, o nível de controle pessoal e o comportamento de procura por êxito ou evitamento do fracasso. Todos esses aspectos, no entanto, são consequência de fatores antecedentes relacionados a um modus operandi do indivíduo, o qual, para alguns autores, está condicionado por um modelo de funcionamento interno específico. Por exemplo, baseando-se na teoria do apego, no padrão seguro/autônomo adolescentes apresentam facilidade de se comunicar e exprimir seus sentimentos com clareza, baixos sinais de ansiedade e depressão, autoconfiança, facilidade de interagir socialmente, percepçáo positiva dos outros e do mundo. No padráo evitante/desapegado, adolescentes tendem a idealizar suas experiências da infância ao mesmo tempo em que têm dificuldades de se lembrar de certas experiências daquele período, apresentando severidade na autocrítica, distanciamento emocional, hostilidade nos relacionamentos, desconfiança dos outros, percepçáo negativa das pessoas e positiva de si mesmo, entre outros. No padrão preocupado/ansioso, os adolescentes apresentam relatos vagos e inconsistentes de experiências da infância, baixa autoestima, percepção positiva dos outros, sinais de depressão, relacionamentos afetivos conflituosos, tendência à introversão, entre outros. No padrão desorganizado/ desorientado, os adolescentes apresentam sinais de desorganização, relatos de vivências negativas em predominância, apontando seus cuidadores como fonte de ameaça e/ou medo, e incongruência afetiva. Tais expressôes dos estilos de apego, por sua vez, podem exercer uma influência determinante na maneira de interpretar resultados de uma competição, na percepção subjetiva das próprias capacidades e no comportamento de procura pelo êxito e evitamento do fracasso.

\section{Consideraçôes Finais}

Há uma tendência no campo desportivo de estudar a motivação a partir de relatos dos próprios atletas, ou do que os mesmos apresentam como comportamento nos períodos pré, durante e pós-competições. No entanto, o argumento aqui defendido aponta para o fato de que o comportamento, assim como os relatos de experiências por parte dos próprios atletas, é resultado de aspectos psicológicos antecedentes, os quais estão inextricavelmente relacionados às e condicionados pelas experiências de relacionamentos de cuidados e afeto durante os primeiros anos de vida, como demonstra a teoria do apego. Portanto, entender o porquê do comportamento de atletas se apresentar de uma maneira ou de outra é de fundamental importância para a predição do comportamento do atleta antes mesmo de uma competiçáo e para o desenvolvimento de abordagens psicológicas que venham a tratar/treinar cada indivíduo de acordo com sua necessidade específica, a qual é subjacente aos e condicionadas pelos estilos de apego de cada um.

Levando-se em consideração, por exemplo, o estilo de apego preocupado/ansioso, é plausível afirmar que a maneira como um atleta interpreta o resultado de uma competiçáo pode estar diretamente relacionada ao fato de que as pessoas que apresentam este estilo de apego tendem a ter baixa autoestima e a se autopunir pelos seus fracassos, ou simplesmente se autoboicotar diante de situações desafiadoras (Dalbem \& Dell'Aglio, 2008). Este tipo de atitude está estreitamente relacionado ao que Heckhausen classifica como comportamento voltado para evitar o fracasso (Samulski, 2009). A diferença entre os dois argumentos está no fato de que Heckhausen classifica o comportamento 
apresentado (como produto final) pelo atleta, e a teoria do apego pode oferecer um insight sobre a origem do problema/evento antes mesmo do produto final. Em outras palavras, pode ajudar a prevenir tal comportamento a partir da antevisão da origem do comportamento em si, a partir da identificação prévia do Modelo Interno de Funcionamento do atleta. Por isso, identificar o estilo de apego de um atleta pode potencialmente servir para antecipar o comportamento deste náo só diante de situaçôes estressantes e desafiadoras, como uma competição de alto nível, mas também durante treinamentos de rotina. Isso, por sua vez, dá ao psicólogo do esporte a vantagem de poder moldar sua atuação nos procedimentos de treinamento psicológico e de atuar de forma mais personalizada com seus atletas.

Finalmente, o campo da teoria do apego ainda se encontra no estágio inicial de exploração, principalmente no Brasil, assim como a Psicologia Esportiva. Novos caminhos que explorem possíveis inter-relaçôes entre esses dois campos de investigação podem trazer benesses para a comunidade científica e leiga, assim como contribuiçôes promissoras para uma melhor atuação de acadêmicos e profissionais da Psicologia Esportiva. Espera-se, portanto, que esta iniciativa teórica inspire também outros pesquisadores a contribuírem com futuras investigaçóes e produçóes nesse domínio.

\section{Referências}

Ainsworth, M.D.S. (1989). The development of infantmother attachment. In B. Caldwell \& H. Ricciuti (Eds.), Review of Child Development Reasearch, (pp. 1-94). Chicago: University of Chicago Press.

Ainsworth, M. D. S., Blehar, M. C., Waters, E., \& Wall, S. (1978). Patterns of attachment: a psychological study of the strange situation. Hillsdale (NJ): Lawrence Erlbaum.

Atilli, G. (2001). Ansia da Separazione e Misura dell'Attacamento Normale e Patologico. Milano: Unicopli.

Atilli, G., Vermigli, P., \& Roazzi, A. (2011). Rearing Styles, Parents' Attachment Mental State, and Children's Social Abilities: The Link to Peer Acceptance. Child Development Research, 1-12.

Belch, E. G., \& Belch, M. A. (2004). Advertising and Promotion ( $6^{a}$ Ed.). Boston: McGraw-Hill.
Blythe, J. (1997). The Essence of Consumer Behaviour. Harlow: Prentice-Hall.

Bowlby, J. (1969). Attachment and loss: Vol. I. London: Hogarth Press.

Bowlby, J. (1973). Attachment and loss: Vol. II. London: Hogarth Press.

Bowlby, J. (1980). Attachment and loss: Vol. III. London: Hogarth Press.

Bradford, E., \& Lyddon, W. (1994). Assessing Adolescent and Adult Attachment: An Update. Journal of Counseling and Development, 73(2), 215-219.

Carr, S. (2009). Implications of attachment theory for sport and physical activity research: conceptual links with achievement goal and peer-relationship models. International Review of Sport and Exercise Psychology, 2(1), 95-115.

Cilo, E. N. P. (2002). Psicologia do esporte: conceitos aplicados a partir da Análise do Comportamento. In A. M. S. Teixeira (Ed.), Ciência do Comportamento: conhecer e avançar, (pp. 119-137). Santo André: ESETec.

Cohn, D. A., Cowan, P. A., Cowan, C. P., \& Pearson, J. (1992). Mothers' and fathers'working models of childhood attachment relationships. Parenting styles and child behavior. Development and Psychopathology, 4, 417-431.

Corriveau, K. H., Harrys, P. L., Meins, E., Fernyhough, C., Arnott, B., Elliot, L., Liddle, B., Hearn, A., Vittorini, L., \& Rosnay, M. (2009). Young children's trust in their mother's claims: longitudinal links with attachment security in infancy. Child Development, 80(3), 750-761.

Dalbem, J. X., \& Dell'Aglio, D. D. (2008). Apego em adolescentes institucionalizadas: processos de resiliência na formação de novos vínculos afetivos. PSICO, 39(1), 33-40.

Dalbem, J. X., \& Dell'Aglio, D. D. (2006). Teoria do apego: bases conceituais e desenvolvimento dos modelos internos de funcionamento. Arquivos Brasileiros de Psicologia, 57, 2006. Acesso em 30 de Agosto de 2010, em http://redalyc.uaemex.mx/ redalyc/pdf/2290/229017444003.pdf

Davis, D., Shaver, P. R., \& Vernon, M. L. (2003). Physical, Emotional, and Behavioral Reactions to Breaking Up: Roles of Gender, Age, Emotional Involvement, and Attachment Style. Personality and Social Psychology Bulletin, 29(7), 871-884. 
Deci, E. L. (1976). Intrinsic Motivation (2 $\left.{ }^{\mathrm{a}} \mathrm{Ed}.\right)$. New York: Plenum Press.

Ein-Dor, T., Mikulincer, M., Doron, G., \& Shaver, P. R. (2010). The Attachment Paradox: How Can So Many of Us (the Insecure Ones) Have No Adaptive Advantages? Perspectives on Psychological Science, 5(2), 123-141.

Epiphanio, E. H. (1999). Psicologia do Esporte: apropriando a desapropriação. Psicologia Ciência e Profissão, 19(3), 70-73.

Éthier, L. S., Lacharité, C., \& Couture, G. (1995). Childhood adversity, parental stress, and depression of negligent mothers. Child Abuse and Neglect, 19(5), 619-632.

Evans, P. (1975). Motivation. London: Methuen.

Main, M., \& Hesse, E. (1990). Parents' unresolved traumatic experiences are related to infant disorganized attachment status: Is frightened and/or frightening parental behavior the linking mechanism? In M. Greenberg, D. Cichetti, M. Cummings (Eds.), Attachment in the preschool years: theory, research and intervention, (pp. 161182). Chicago: University Press.

Main, M., Kaplan, N., \& Cassidy, J. (1985). Security in infancy, childhood, and adulthood: a move to the level of representation. Monographs of the Society for Research in Child Development, 50, 66104.

Mallinckrodt, B., \& Wang, C. (2004). Quantitative methods for verifying semantic equivalence of translated research instruments: a Chinese version of the experiences in close relationships scale. Journal of Counseling Psychology, 51(3), 368-379.

Mowen, J. C., \& Minor, M. (1998). Consumer Behaviour ( $5^{\mathrm{a}} \mathrm{Ed}$.). New Jersey: Prentice Hall.

Ng, K., \& Smith, S. D. (2006). The Relationship Between Attachment Theory and Intergenerational Family Systems Theory. The Family Journal: Counseling and Therapy for Couples and Families, 14(4), 430-440.

Obegi, J. H., Morrison, T. L., \& Shaver, P. R. (2004). Exploring intergenerational transmission of attachment style in young female adults and their mothers. Journal of Social and Personal Relationships, 21(5), 625-638.

Parkinson, B., \& Colman, A. M. (1995). Emotion and Motivation. London: Longman.

Parrott, W. G. (2001). Emotions in Social Psychology. Philadelphia: Psychology Press.
Pickton, D., \& Broderick, A. (2005). Integrated Marketing Communications ( $2^{a}$ Ed.). London: Prentice Hall.

Punyanunt-Carter, N. M. (2006). Evaluating the Effects of Attachment Styles on Relationship Maintenance Behaviors in Father-Daughter Relationships. The Family Journal: Counseling and Therapy for Couples and Families, 14(2), 135-143.

Reeve, J. (2005). Understanding Motivation and Emotion (4 ${ }^{\mathrm{a}} \mathrm{Ed}$.). Iwoa: Wiley.

Román, S., \& Savoia, M. G. (2003). Pensamentos automáticos e ansiedade num grupo de jogadores de futebol de campo. Psicologia: Teoria e Prática, 5(2), 13-22.

Rubio, K. (2007). Da psicologia do esporte que temos à psicologia do esporte que queremos. Revista Brasileira de Psicologia do Esporte, 1(1).

Rubio, K. (1999). A Psicologia do Esporte: histórico e áreas de atuação e pesquisa. Psicologia Ciência e Profissáo, 19(3), 60-69.

Samulski, D. (2009). Psicologia do Esporte: conceitos e novas perspectivas (2a Ed.). Barueri: Manole.

Samulski, D., \& Noce, F. A. (2000). A importância da atividade física para a saúde e qualidade de vida. Revista Brasileira de Atividade Física e Saúde, 5, 5-21.

Sanches, S. M. (2007). A prática esportiva como uma atividade potencialmente promotora de resiliência. Revista Brasileira de Psicologia do Esporte, 1(1).

Santos, A. R. R. (2005). Fair play e a prática de esportes. Revista Mackenzie de Educação Física e Esportes, 4(4), 13-28.

Santos, A. R. R. (2001). O Espírito Esportivo entre Universitários de Educação Física e Psicologia, da Cidade do Recife, Pernambuco, Brasil. Corporis, 1(1), 47-53, 2001.

Shomaker, L., \& Furman, W. (2009). Parentadolescent relationship qualities, internal working models, and attachment styles as predictors of adolescents' interactions with friends. Journal of Social and Personal Relationships, 26(5), 579-603.

Sousa Filho, P. G. (2000). O que é a Psicologia dos Esportes. Revista Brasileira Ciência e Movimento, 8(4), 33-36.

Steenkamp, J. E. M. (2001).The role of national culture in international marketing research. International Marketing Review, 18(1), 30-44. 
Tacón, A. M., \& Caldera, Y. M. (2001). Attachment and Parental Correlates in Late Adolescent Mexican Women. Hispanic Journal of Behavioral Science, 23(1), 71-87.

Vernon, M. D. (1971). Human Motivation ( $2^{a}$ Ed.). London: Cambridge University Press.

Vilani, L. H. P., \& Samulski, D. M. (2002). Família e esporte: uma revisão sobre a influência dos pais na carreira esportiva de crianças e adolescentes. In G. E. Silami \& K. L. M. Lemos (Eds.), Temas Atuais VII: Educação Física e Esportes, (pp. 9-26). Belo Horizonte: Editora Health.

\section{Endereço para correspondência:}

Avenida Acad. Hélio Ramos, s/n - CFCH, 8 o Andar CEP 50670-901 - Recife/PE

E-mail: marcilioangelo@hotmail.com

Recebido em 03/04/2012

Revisto em 27/10/2012

Aceito em 20/11/2012 